\title{
Students Engagement and Learning through the Development of Didactic Models for Mechanical Engineering
}

\author{
Pérez M. , Ayerdi V, Arroyo Z. \\ Department of Mechanical Engineering, Faculty of Engineering, Universidad del Valle de Guatemala, Guatemala \\ *Corresponding Author: arr12278@uvg.edu.gt,mperez@uvg.edu.gt, vhayerdi@uvg.edu.gt
}

Copyright $(\mathrm{O} 2018$ by authors, all rights reserved. Authors agree that this article remains permanently open access under the terms of the Creative Commons Attribution License 4.0 International License

\begin{abstract}
Eight mechanical engineering students built three didactic models that show how different mechanical elements and mechanisms work in a pick-up truck. This study reviews their experience while manufacturing them, challenges faced and their learning experience. The project was directed by students entirely which posed planning, organizing, manufacturing and fundraising challenges. The biggest technical challenge was cutting open certain parts of the models to expose internal mechanisms; it was overcome combining different manufacturing strategies and equipment at hand. Every challenge was confronted as a team helping develop leadership, group work and other human skills. The further impact and usage of the models built was analyzed through polls sent to professors and students using them for different classes such as introduction to mechanical engineering, mechanical design and material sciences. The models have facilitated learning complex concepts, generated more open discussions, made learning more interactive, created enthusiasm and curiosity amongst students.
\end{abstract}

Keywords Didactic Models, Mechanical Engineering, Teaching Resources

\section{Introduction}

Engineering education around the world relies largely on lectured based classes, solving textbook problems and theoretical knowledge. However, there are several other skills needed for the engineering professional such as teamwork and communication, creativity and design, coping and adapting to changes in the working environment [1][2].

Creating a good environment during classes benefits both teachers and students. Changing sometimes that environment from a traditional classroom to a metal workshop, collaborative spaces give students tools that will help them in the real world [3], and changing books for didactic models helps meet more diverse students' needs, as a variety in tasks is recommended to address the different learning styles [4]. Using physical materials in a learning task might change the nature of the knowledge gained, also stimulates the students' multiple senses and thus provides a more complete view increase students' interest in learning" [5][6]. All the previous enhances student behavior and achievement, since it depends on how the student makes use of his/her environmental resources, and makes teachers more satisfied with their job. Studies show that students disengaged perform worse over time [7][8].

This study examines the students' perspective on a practical experience, compares it to the traditional engineering education and evaluates the impact over their own educational experience. First it examines the experience of a group of students who developed didactic models for mechanical engineering; designing and managing the project, relating theory to practice, and incorporating human skills with technical skills. A team of 8 mechanical engineering students drove the project entirely facing design, technical and economic challenges as a team. It took almost one year of work and approximately 500 man hours to create three didactic models with an estimated cost of nearly $\$ 5,000$. [9] Finally, reviews the experience of teachers and other students using said models for better engagement and a deeper learning experience.

\section{Methodology}

This study is experience centered; most qualitative data has been collected through semi-structured interviews with students who worked on making the models. The topics of the interviews were: main challenges faced and how they 
solved them, what was learned during the project, skills developed during the project and personal experience. Afterwards a poll was sent to students to rate their knowledge and comfort in several aspects before and after the project. To evaluate teachers' and students' perspective on using the model a poll was elaborated. Most questions were open ended or multiple selections. For teachers the poll had 7 questions that focused on how they use the models as a teaching resource, how frequently and if they have observed any benefits. For students the poll had 6 questions regarding their learning preferences and any benefits or impact of using the models. Both polls can be seen detailed in the appendix. All polls were designed by the mechanical engineering department and approved by the head of the department. They were then sent via e-mail to students and professors with a two week response period.

\section{Results}

While building each didactic model students learned hey each required a different strategy and planning, whether it was because of the size, shape, tools required, or the amount of work (cleaning, lubrication, paint, cutting) that it needed. The first model was simpler, but students perceived their lack of experience with some equipment prolonged the work timeline.

Another significant challenge was the state in which they found the pickup truck; it had been abandoned for over 5 years, accumulating dust and rust. This implied taking extra time during the cleaning stage.

When making the models students learned several technical lessons. Creating openings or windows on components in order to see interior mechanisms, taught them about materials and manufacturing equipment. Fig 1 shows the windows made on the gearbox model.

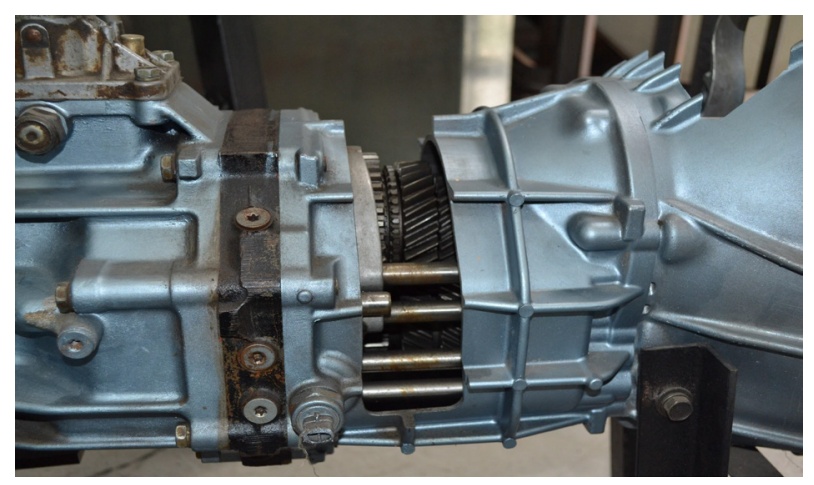

Figure 1. Gearbox model opening

For this model they had to use different manufacturing strategies limited by the equipment at hand. The irregular shapes of the components and the restricted capacity of the equipment, forced them to do them in different phases. To achieve a large window, the cuts were made using a combination of equipment such as: milling machine, hand drill, saw and angle grinder. This process was very time consuming; during this stage each student spent between 2 to 3 hours, one or two days a week. Most of the students were not very comfortable handling tools at first, through the project they practiced and learned how to use them.

Students also learned to make technical decisions with the first model, the rear chassis model, in order to open the windows in the brake's drum and in the differential, which was quite a challenge. The drum was cut in the milling machine and rust was removed using the lathe and some sandpaper. With the differential the angle grinder was used, since the size exceeded the milling machine's capacity.

During the project the students indicated that have learned a lot about mechanisms and mechanical components while they were disassembling and reassembling them. Several mechanisms were new to them and required researching their functionality and components. Sometimes they did not know how to put them together so manuals, videos and professors were consulted. The braking system from the first model was one of the most challenging, because of the amount of components it had and the little information students knew about it at the time.

Students realized that project planning and managing a group of volunteers was harder than it seemed. On figure 2, the final project timeline is shown, but it took several iterations and corrections. The project helped students develop skills such as leadership, time management, organization, project planning and teamwork. In table 1, the time consumed at different stages of the project and the number of students involved are detailed. The difficulty level was assessed by students ranging from 1 (low difficulty) to 5 (high difficulty).

\begin{tabular}{|l|c|c|c|c|c|c|c|c|c|}
\hline \multicolumn{1}{|c|}{ Year } & \multicolumn{3}{c|}{2014} & \multicolumn{5}{c|}{2015} \\
\hline \multicolumn{1}{|c|}{ Month } & Jul & Aug & Sep & Oct & Jan & Feb & Mar & Apr & May \\
\hline Planning & & & & & & & & & \\
\hline Dismantling & & & & & & & & & \\
\hline Out and separation & & & & & & & & & \\
\hline Funding activities & & & & & & & & & \\
\hline Rear section & & & & & & & & & \\
\hline Transmission module & & & & & & & & & \\
\hline Engine module & & & & & & & & & \\
\hline
\end{tabular}

Figure 2. Duration and stages of the project

Table 1. Difficulty rating of stages

\begin{tabular}{|c|c|c|c|}
\hline Stage & $\begin{array}{c}\text { Difficulty Level } \\
(1-5)\end{array}$ & $\begin{array}{c}\text { Number of } \\
\text { students }\end{array}$ & $\begin{array}{c}\text { Total hours } \\
\text { employed }\end{array}$ \\
\hline 1 & 3 & 3 & 30 \\
\hline 2 & 2 & 8 & 80 \\
\hline 3 & 2 & 5 & 55 \\
\hline 4 & 2 & 4 & 25 \\
\hline 5 & 3 & 6 & 110 \\
\hline 6 & 4 & 3 & 100 \\
\hline 7 & 5 & 3 & 120 \\
\hline
\end{tabular}


Out of the eight students that worked on the project, five answered a poll evaluating their skills and knowledge at the beginning and at the end of the project. The aspects rated from how much did they knew about automotive mechanics, mechanisms (Fig.3), mechanical elements and materials; to how comfortable they were with hand tools (Fig. 4), electric tools and managing projects. Students rated all aspects higher after the project, reflecting their progress and learning.

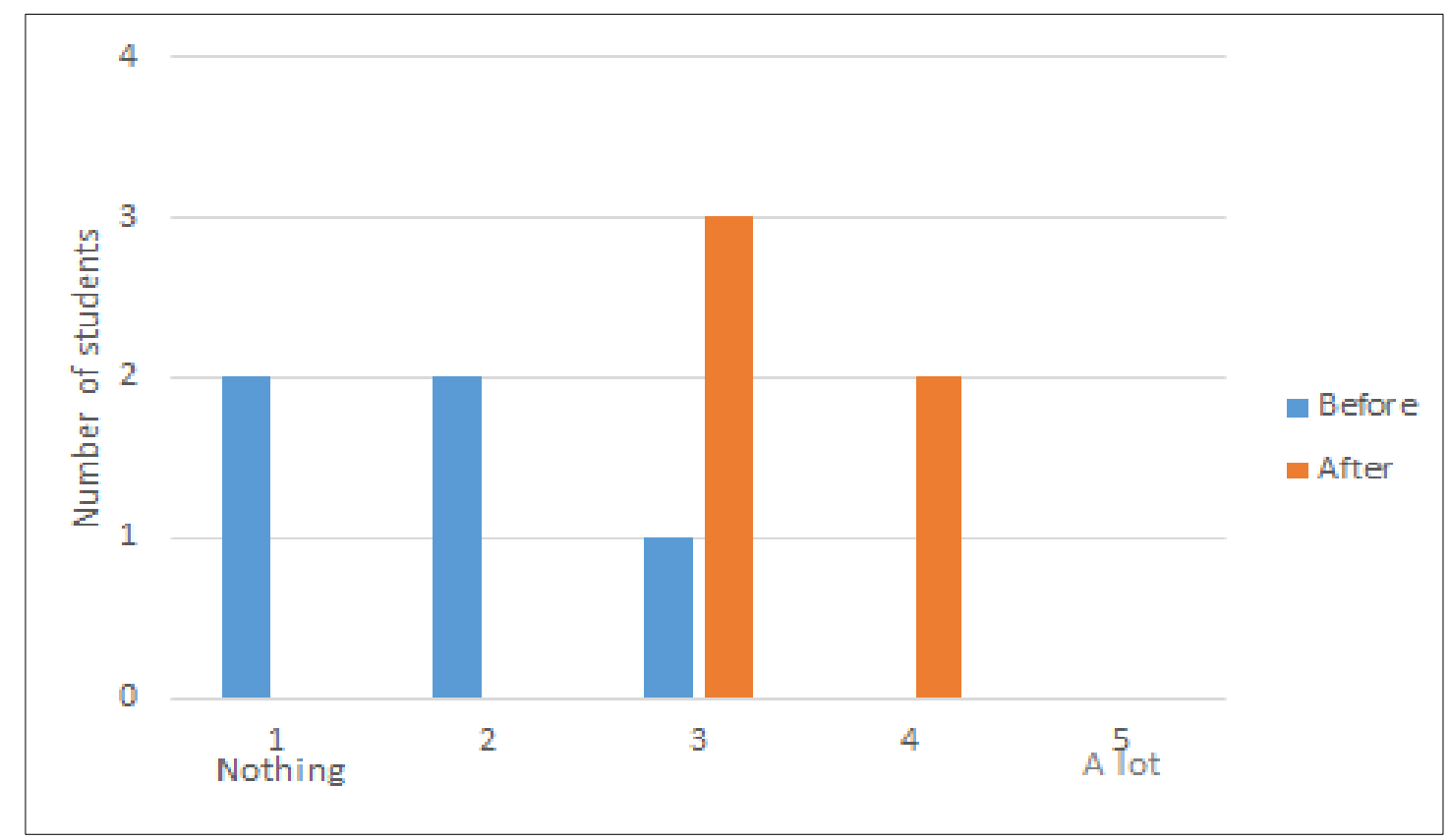

Figure 3. Increase in mechanisms' knowledge

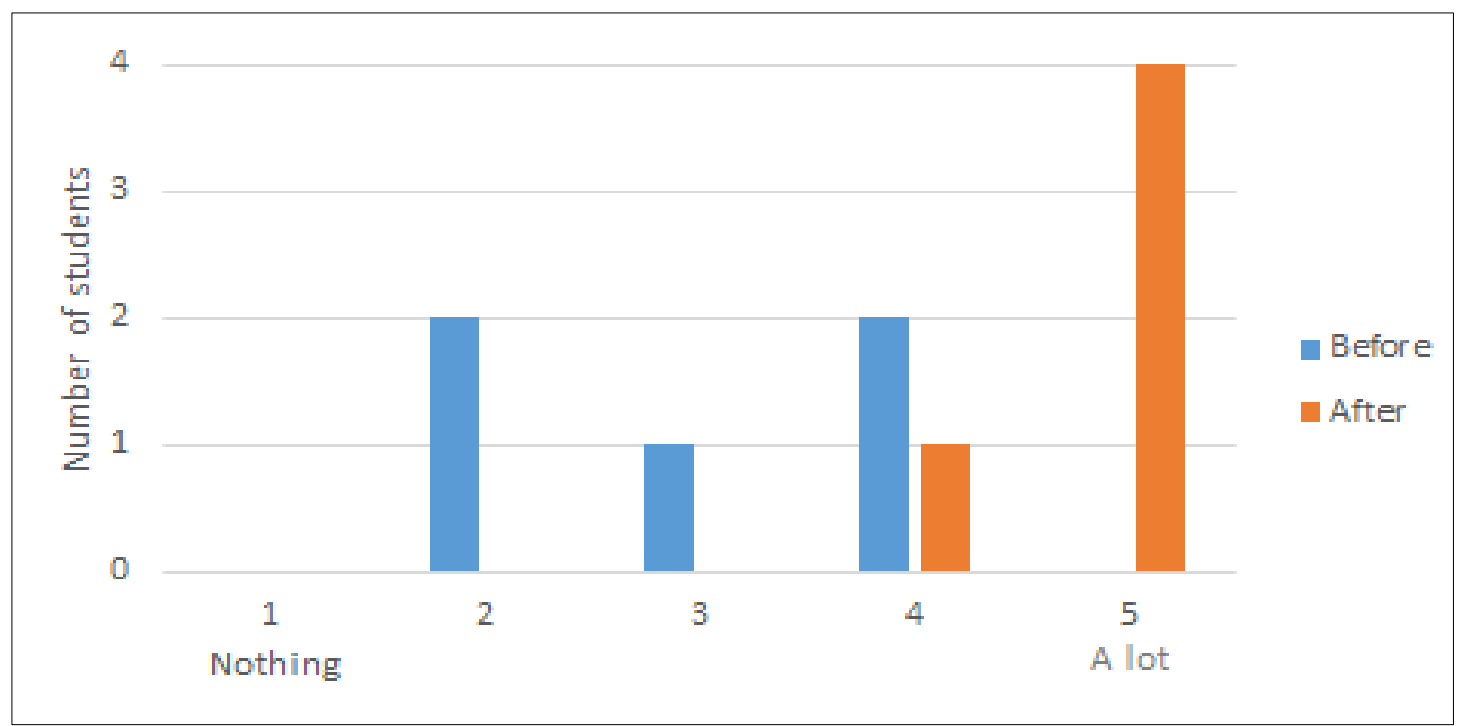

Figure 4. Increase in comfort while handling tools

After the models were finished they were permanently placed at "Maker 502" makerspace. Students and teachers have free access to them.

At the end of the first semester a poll was sent to 68 mechanical engineering students, 21 students (31\%) answered, to know if the models are being of help and how often are they using them. From it was obtained that $81 \%$ of students were on their fourth or fifth year. Frequency of usage of the models is shown on figure 5 below. 


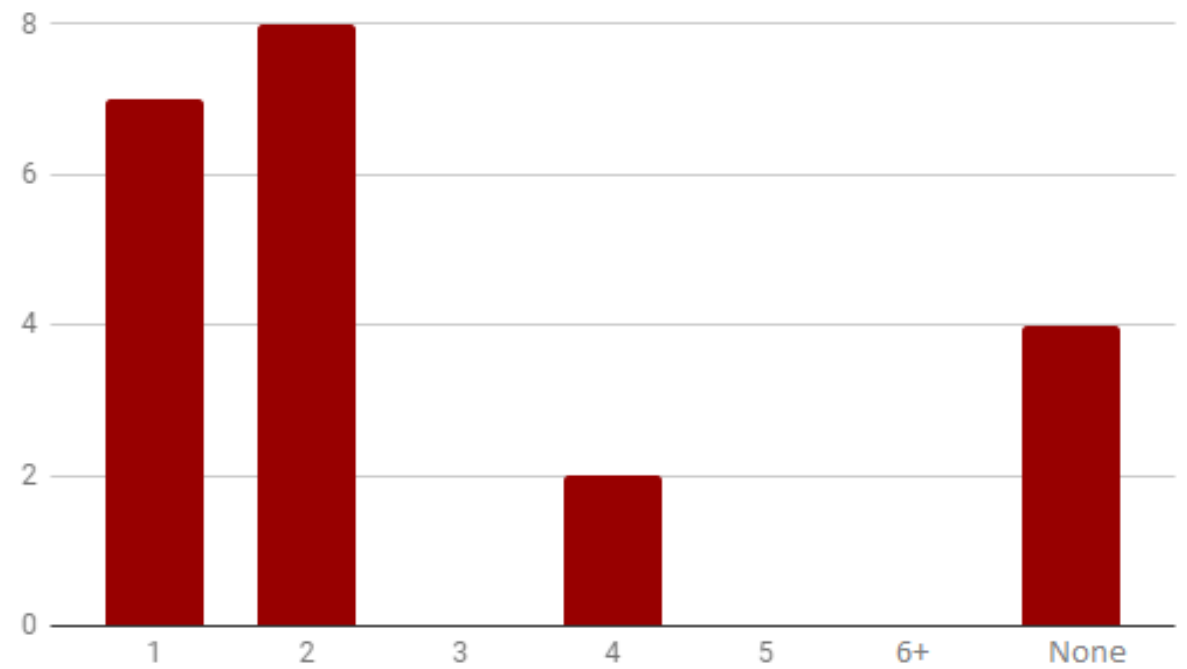

Figure 5. Usage of models since beginning of career

When asked about preferences regarding learning methods $81 \%$ of students prefer using the models, the remaining $19 \%$ was divided in learning through projects, videos and traditional classes.

$90.5 \%$ of students think the models have contributed to their learning, identifying some of the major benefits as follows: physical interaction with the models allows a better understanding of their functioning; seeing the model and elements analyzed at work helps better understand all the concepts behind it; visualizing what was learned theoretically making classes more interesting; classmates can also comment and share their knowledge using the models; when using a book it is common that the scenario is a simplified version while the model shows aspects of the design that haven't been thought of. Figure 6 shows the aspects students think the models reinforce.

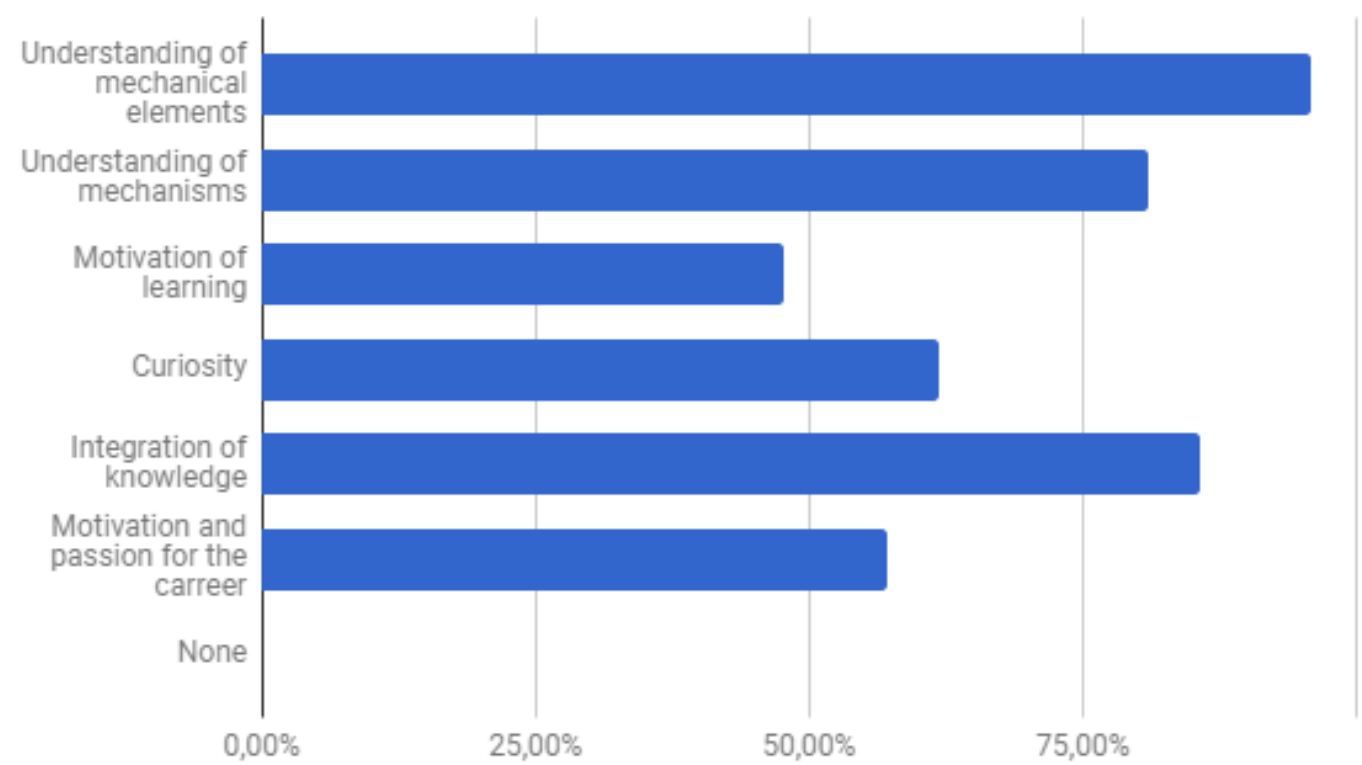

Figure 6. Aspects the models reinforce according to students

A second poll was sent to mechanical engineering professors, four out of seven (57\%) answered, to know if the models are helpful as a teaching aid. From it they indicated using them from one to three times during the semester for "Introduction to Mechanical Engineering" and "Mechanical Design" courses. The use of the models varied from: exemplifying concepts such as applications for materials; reverse engineering of components to figure out their functioning; a study guide to analyze and discuss each model; and assigning students a lecture on specific mechanisms and components to later identify them on the models and learn about their function.

Professors indicated they use the models because it helps the student visualize concepts and retain the knowledge better. 
As one professor said in the poll: it gives them "better understanding, deeper learning (harder to forget concepts) and more interest in learning". Most of the mechanisms and systems that are being taught are too complex to represent in a single image so they rather have the students analyze the models to learn beyond their theoretical interaction. Professors said the main benefits of integrating the models to their classes are: a better understanding of concepts seen during class; greater enthusiasm for learning; generating more open discussions; better understanding of the size of elements and systems; facilitating the understanding of their functioning; makes the learning experience more fluid and entertaining, making it easier to grasp the interest of a diverse group of students.

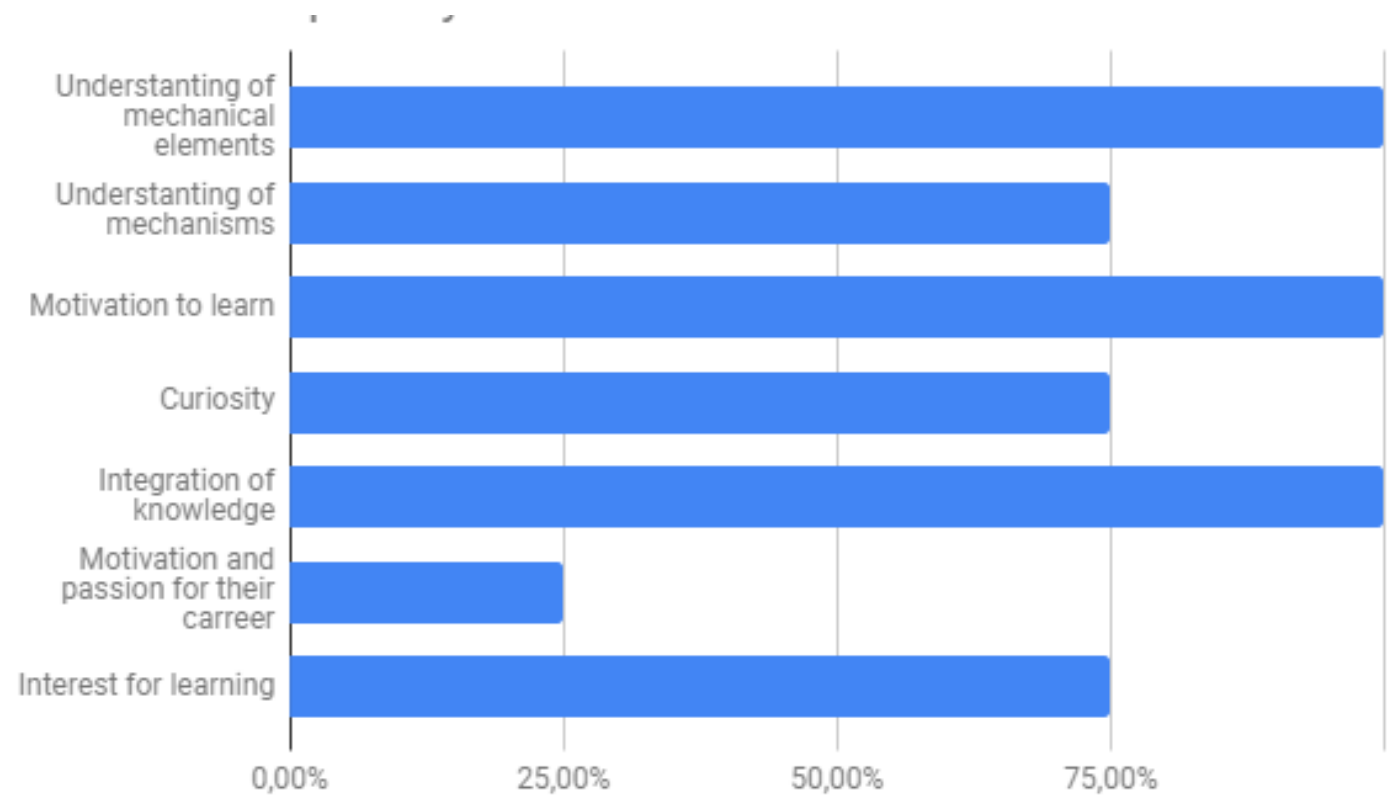

Figure 7. Aspects the models reinforce according to professors

\section{Discussion}

Research has defined engagement in three ways: Behavioral, which includes involvement in academic and on-task behavior. Emotional, related to student attitudes and student interest and values, and cognitive related to motivational goals and self-regulated learning [10]. In this case behavioral engagement was tested while students organized a project by themselves. From their experience with the didactic models, students found that projects pose a different kind of challenge, which can lead to an intrinsic motivation to learn. One of the key factors was that the students were completely in charge of the project. They were able to organize the whole project from fundraising to planning and executing each stage of it; going by work schedules, work groups, machining processes used, appearance improvements, etc. Being responsible for the project generated a commitment to create something that would later help other students as well. It gave them a sense of accomplishment because they were transferring everything learned on paper into something tangible and defying their own limits in the process. It is worth mentioning that the guidance of the staff was also the key for students to take the right track during each stage and help overcome the obstacles presented.

This project was focused on students not learning only from text books, but from realistic models that helped them understand certain concepts. However, the experience obtained by the students that made them, all the knowledge and sense of achievement acquired led them to motivate their classmates so that they can get involved in similar projects or even create their own and execute them. This is why the diffuse and use of the models became so important. The main objective was fulfilled with the first 8 students; the next step was that the rest of the students could have hands on learning experience during classes through the didactic models.

The models were used for the first time in several classes of the first semester of 2017. Students expressed to the department they appreciated using these models because there was an improvement in their understanding of pieces and movements that were not clear in the textbooks. Due to this, polls were made at the beginning of 2018 in order to have a quantitative and qualitative marker and measure the improvements perceived.

The two courses where the models are used, "Introduction to Mechanical Engineering" and "Mechanical Design", have as general competencies: to develop critical thinking and analysis, work collaboratively with others, solve problems in a creative way, use technology adequately and research different areas of knowledge. The didactic models directly support three of 
these competencies: develop critical thinking and analysis, work collaboratively with others, and research different areas of knowledge. Furthermore, for the "Introduction to Mechanical Engineering", which is a first year course, the models help students to get to know how machines work, to observe different mechanical elements and to get familiar with the design process in engineering. For the Mechanical Design course the models support specifical skills such as: understanding basic design criteria by analyzing existing systems and designing and selecting different mechanical elements by showing real world application such as different types of gears, belts and chains within a system to transmit power. After consulting students and professors about the use of didactic models, both groups agreed upon the improved learning experience they provide. The response rate with the student poll was $31 \%$ and $57 \%$ among professors. .Both agreed the models' prime benefit is to facilitate the understanding of mechanical elements and mechanisms. It seems professors perceive the models create greater motivation to learn than what students recognized. On the other hand, students indicated they felt more motivated and passionate for their career than what professors perceived.

This was the first didactic model for the mechanical engineering department (at UVG) to be built completely by students on an extracurricular basis. Although the total cost of the project might seem elevated, $90 \%$ of it consists of using the existing equipment at the metal shop and supervision from the shop's technician.

\section{Conclusions}

Although being a one-time project, the didactic models created by students have contributed in different levels and have a great potential to support and enhance learning for future students using them. First, they served as a learning and personal growth experience for the eight students that worked on them directly. Second, they have been a teaching aid for professors to illustrate complex concepts. Third, several students have benefited from having these models available and integrated during classes, making it easier to understand mechanical elements and mechanisms. The models have also created more curiosity, motivation and passion for the career among students. These benefits outweigh the cost, especially since the university already had the equipment and technician available. This suggests other institutions might benefit as well from empowering their students to create didactic models with the tools and equipment available. Finally, the creation of the models has proved that it is possible for students to work on self-driven projects that can impact their education and their fellow classmate's learning experience.

\section{Appendix}

Before and after evaluation for building didactic models

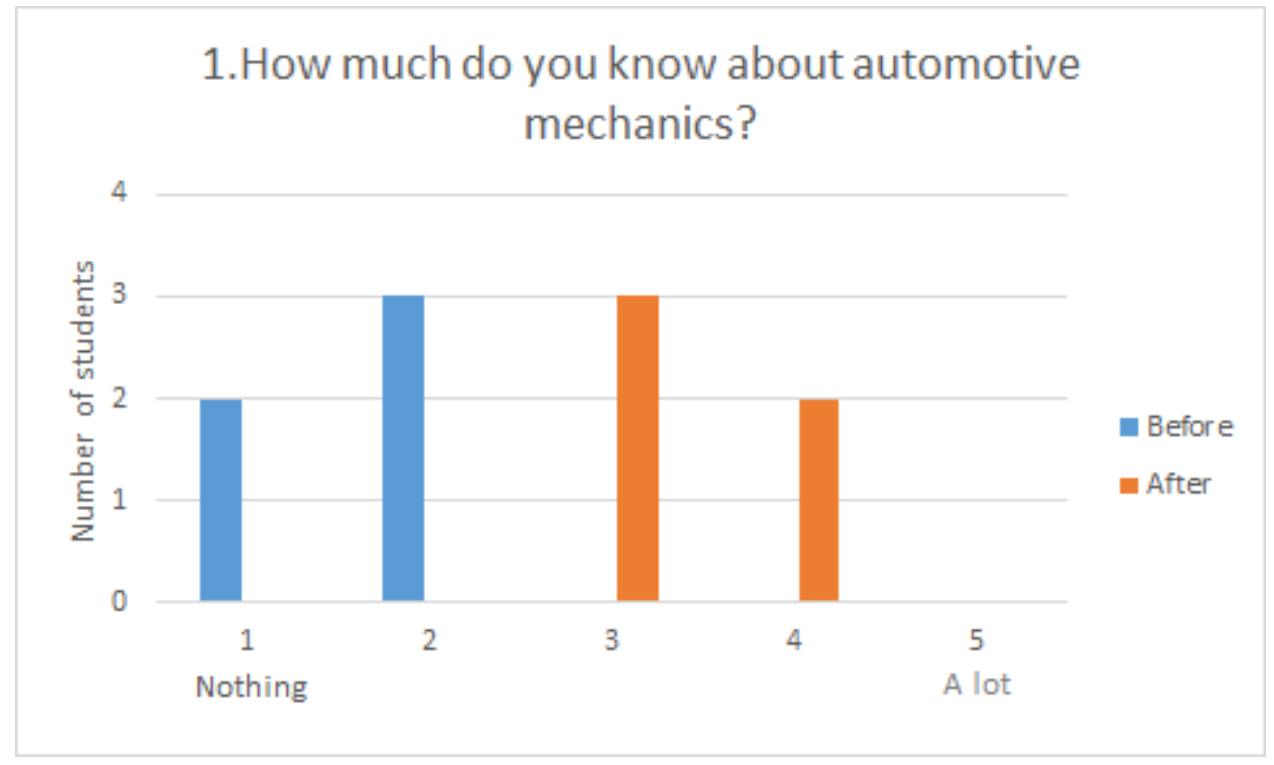



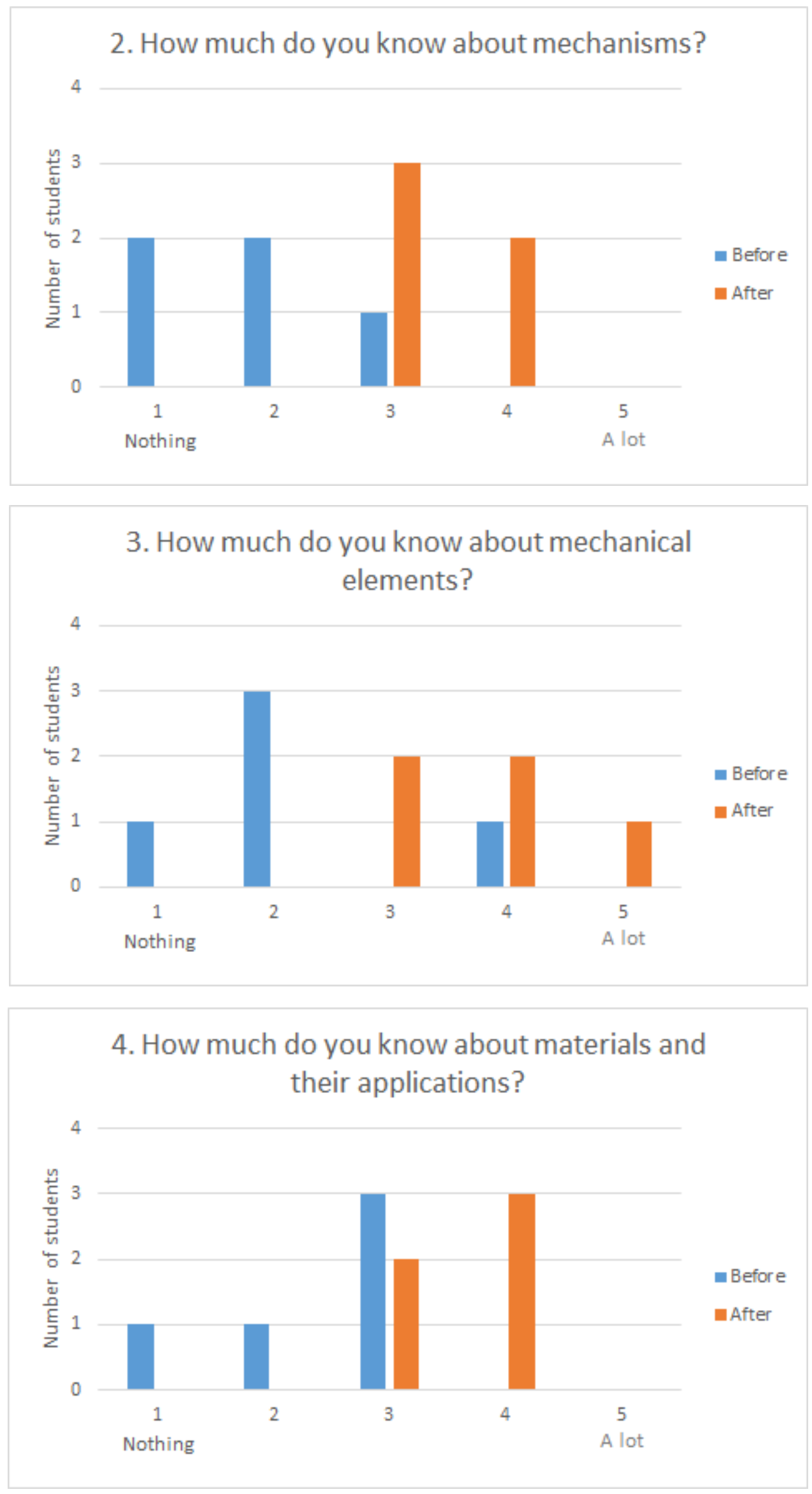


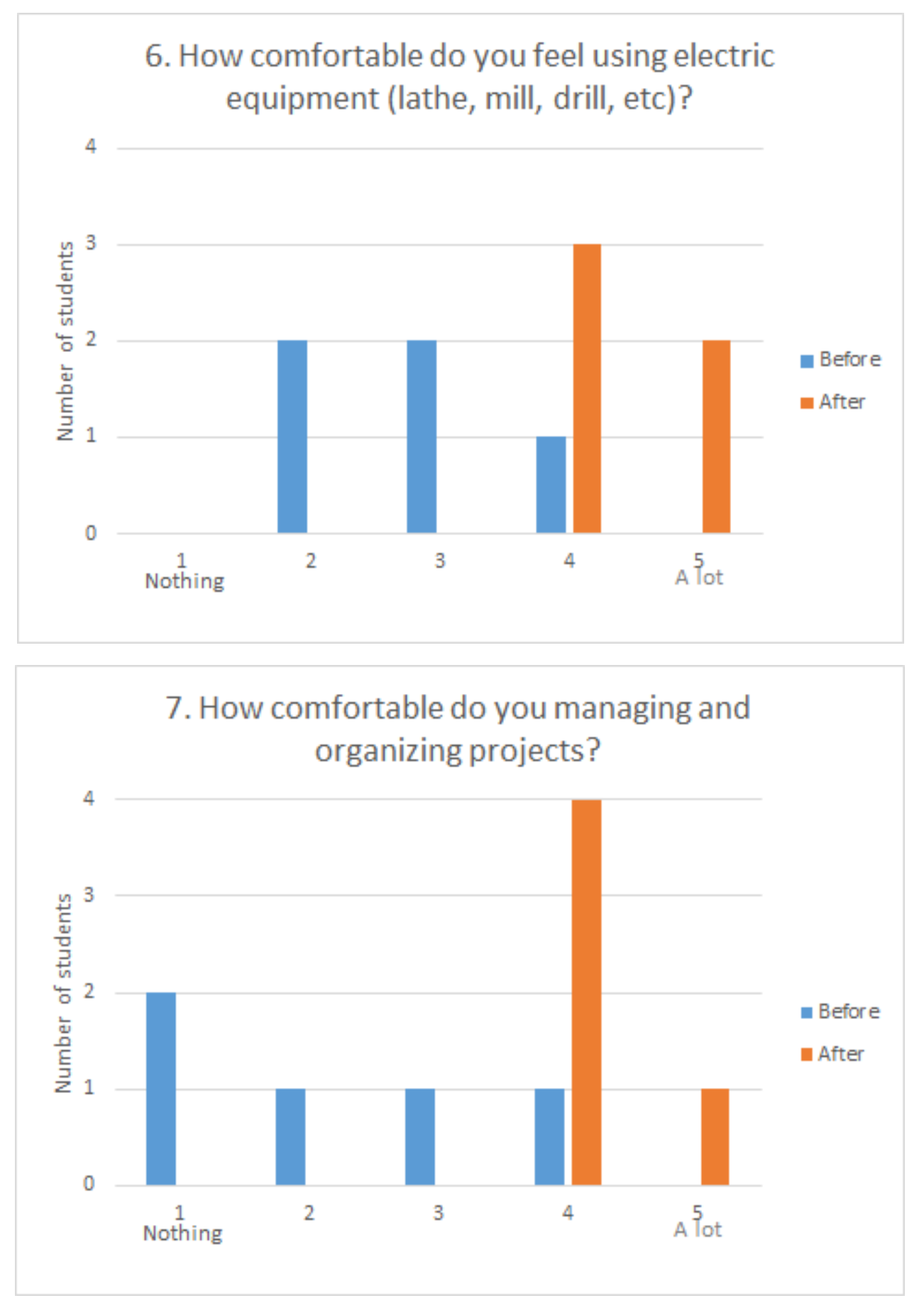

Poll sent to students 


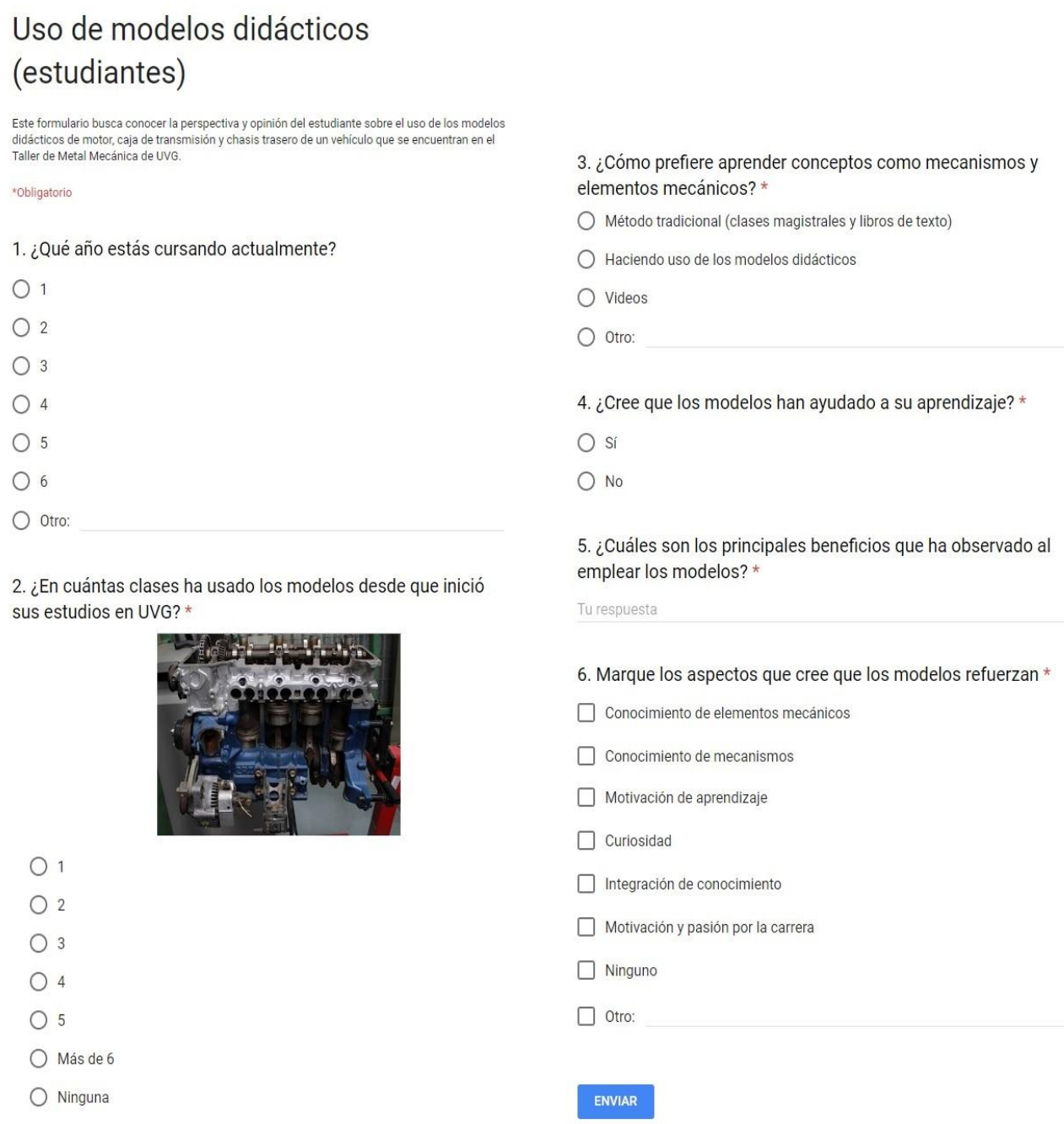

Poll sent to teachers 


\section{Modelos didácticos}

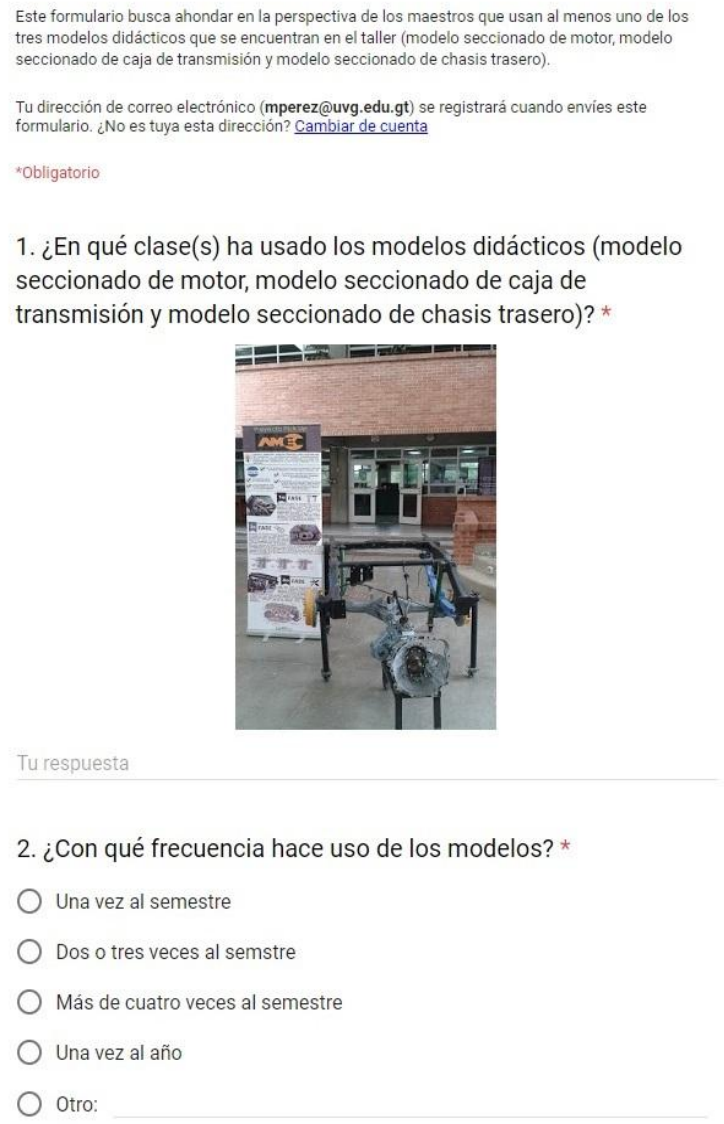

3. Describa cómo usa los modelos didácticos en su clase *

Tu respuesta

\section{REFERENCES}

[1] Henshaw, R., Desirable attributes for professional engineers. In Agnew, J.B. \& Creswell, C. (Eds.) Broadening Horizons of Engineering Education, 3rd Annual conference of Australasian Association for Engineering Education. 15-18 December, 1991. University of Adelaide. 199-204 (1991).

[2] Lang, J.D., Cruise, S., McVey, F.D. \& McMasters, J., Industry expectations of new engineers: A survey to assist curriculum designers. Journal of Engineering Education, 88, 1, 43-51, (1999).

[3] Goss, Peter, Julie Sonnemann, and Kate Griffiths. 2017. Engaging Students: Creating Classrooms That Improve Learning. http://www.grattan.edu.au/.

[4] Felder, Brent. Understanding Students Differences. Journal of Engineering Education, 94,1, 57-72, (2005).

[5] Y.-C. Chen, H.-L. Chi, W.-H. Hung, and S.-C. Kang, "Use of Tangible and Augmented Reality Models in Engineering

\author{
4. ¿Por qué razón los utiliza como modelos didácticos? * \\ Tu respuesta \\ 5. ¿Cuáles son los principales beneficios que ha observado al \\ emplear los modelos? * \\ Tu respuesta \\ 6. ¿Qué sugerencias tiene en referencia a los modelos \\ didácticos? * \\ Tu respuesta
}

7. Marque los aspectos que cree que los modelos refuerzan en los estudiantes *

Conocimiento de elementos mecánico
Conocimiento de mecanismos
Curiosidación de aprendizaje
Integración de conocimiento
Motivación y pasión por la carrera
Interés por el aprendizaje
Otro:
ENVIAR

Graphics Courses,” J. Prof. Issues Eng. Educ. Pract., vol. 137, no. 4, pp. 267-276, 2011.

[6] S. Wood, W. Goodridge, B. Call, and T. Sweeten, "Preliminary Analysis of Spatial Ability Improvement within an Engineering Mechanics Course: Statics," 2016 ASEE Annu. Conf. Expo. Proc., p. 25942, 2016.

[7] Shafiuddin, Mohammed. 2010. "Cooperative Learning Approach in Learning." 2(4): 589-95.

[8] Krause, Kerri-Lee, and Hamish Coates. 2008. "Students' Engagement in First-Year University." Assessment \& Evaluation in Higher Education 33(5): 493-505. http://www.tandfonline.com/doi/abs/10.1080/02602930701 698892 .

[9] Pérez M., Arroyo Z., Reyes S., Rossino R., Rocha A. and Ayerdi V. Using makerspaces to develop didactic models for mechanical engineering. Proceedings of the 1st International Symposium on Academic Makerspaces (ISAM). 13-16 November, 2016. Massachusetts Institute of Technology.

[10] Concept, A Cognitive-affective, S. Sharan, and I.G.C. Tan. 2008. "Student Engagement in Learning." Organizing Schools for Productive Learning: 41-45. 